\title{
Saudi Arabian Pre-Service Special Education Teachers Knowledge of Attention-Deficit/Hyperactivity Disorder (ADHD)
}

\author{
Al-Hwaiti Mohammed ${ }^{1}$ \\ ${ }^{1}$ School of Education, Umm Al-Qura University, Makkah, Saudi Arabia \\ Correspondence: Al-Hwaiti Mohammed, Department of Special Education, Umm Al-QuraUniversity, Makkah, \\ P.O. box715, Saudi Arabia. Tel: 96-612-527-0000. E- mail: mhhwaiti@uqu.edu.sa
}

Received: October 25, 2018 Accepted: January 24, 2019 Online Published: February 21, 2019

doi:10.5539/gjhs.v11n3p32 URL: https://doi.org/10.5539/gjhs.v11n3p32

\begin{abstract}
The current study aims at detecting the level of knowledge held by special education student teachers at Umm Al-Qura University with regard to Attention-Deficit/Hyperactivity Disorder (ADHD), and comparing their level of knowledge of (ADHD) according to variables: Gender (male or female), track or specialty (special education ,mental disability, learning disabilities, hearing disability, behavioral disorders and Behavioral Disorders and Autism), school year or university level (first year, second year, third year, and fourth year). The sample of the study consists of (682) students who were selected randomly from the Department of Special Education at Umm Al-Qura University in Makkah in the Kingdom of Saudi Arabia for the academic year (1437H-1438H), and SPSS was applied for data analysis. The results showed that Saudi Arabian Pre-Service Special Education Teachers' overall knowledge is high (64.2\%). The correct rate of knowledge of ADHD was (93.0 \%) and (86.8) ('high'), respectively. As for the sex differences were in favor of females, as for year and track or specialty variables, Pairwise Multiple Comparisons Post Hoc Test using LSD method. Implications of the study results are discussed, and recommendations are presented.
\end{abstract}

Keywords: knowledge of ADHD, pre-service teachers, Saudi Arabia, special education

\section{Introduction}

Amid the most recent three decades, numerous articles have raised worries about the issue of Attention-shortage/hyperactivity issue (Barbaresi et al., 2002; Kos et al., 2006; Bener et al., 2008; Kang et al., 2011; Dilaimi, 2013; Alamri, 2014; Suleiman, 2015; Lee \& Witruk, 2016; Alshboul, 2017; Lee, 2017). From the minute kids with ADHD enter the school, they bear on their shoulders a social weight. The capacity to sit set up, to tune in, to think, to comply, to limit hasty conduct, to collaborate, to be composed, and to play out the directions, just as to share, to play pleasantly, and to frame charming relations with other youngsters, is an essential condition for accomplishment in the investigations. Youthful youngsters with ADHD go to the grade school when they are now behind whatever remains of their age assemble in scholarly aptitudes (O'Reilly, 2002).

Attention-deficit/hyperactivity disorder (ADHD) is defined as 'a persistent pattern of inattention and/or hyperactivity-impulsivity that interferes with functioning or development' ADHD is highly prevalent among school-aged children with a reported prevalence of 5\% in children (American Psychiatric Association, 2013, p. 61).

pervasiveness converts into roughly one understudy in each classroom having a finding of ADHD (Mulholland, Cumming, \& Jung, 2015). As indicated by (Al-Modayfer et al., 2015) the commonness of ADHD in Saudi Arabia was $(8.4 \%)$. ADHD has essential and wide consequences for the functioning and development of affected children as well as having a considerable impact on others including family members, peers, and teachers (Wehmeier et al., 2010).

ADHD-type behaviors can often conceal comorbid learning disabilities, which left covered up can has a critical long-lasting effect. Children with ADHD are multiple times bound to has a learning disability than children without ADHD (Mayes, Calhoun, \& Crowell, 2000), It is important to perceive that ADHD presentations change over time and developmental stages. Besides, many children with ADHD have a specific learning disorder (Masi \& Gignac, 2015) besides the behaviors associated with ADHD can be exceptionally troublesome to the learning and social condition of the classroom. The behaviors are inclusive of, but not limited to: (a) off-task behaviors, (b) 
poor peer interactions, (c) difficulty following directions, (d) climbing and running when inappropriate, and (e) inability to refrain from interrupting during conversations (Ohan, et al., 2011). However, ADHD is still not completely understood and remains under scientific study (Bener et al., 2006).

As noted, ADHD is a complex disorder of impairment of brain functions, which burdens society with significant financial costs. Its salient features are inattention, hyperactivity, and impulsivity. In many cases, it is accompanied by one or more serious psychiatric comorbidities. Criteria for its diagnosis have emerged over the past four decades, resulting in better recognition and more widespread treatment (Hanna, 2009). The Diagnostic and Statistical Manual of Mental Disorders - 5th edition (DSM-5) defines ADHD as a persistent pattern of inattention and/or hyperactivity-impulsivity that interferes with functioning or development as characterized by six or more symptoms from either or both the inattention group of criteria and the hyperactivity and impulsivity criteria (5th ed.; DSM-5; American Psychiatric Association, 2013). The symptoms presenting in two or more settings (e.g. at home, school, or work; with friends or relatives; in other activities) and the symptoms have persisted for at least 6 months to a degree that is inconsistent with developmental level and adversely effects directly on social, academic or occupational functioning. Several symptoms must have been present before the age of 12 years.

Saudi Arabia, due to difficulty in observing young children, ADHD is frequently diagnosed when the child attends school and exhibits compatible diagnostic symptoms such as inattention or compulsivity. To make a determination of ADHD, it also requires the symptoms to be apparent in at least two different situations or places. Likewise, teachers' observation of the child's behavior is crucial in diagnosing ADHD (American Academy of Pediatrics, 2000).

Teachers are frequently the first to detect ADHD-type behaviors, and the diagnostic process regularly starts with a referral from a classroom teacher (Norvilitis \& Fang, 2005). Thus, it is important that teachers' Knowledge of ADHD are able to be adequately appraised (Mulholland, 2016).

Since there is a high probability that they will need to oversee understudies with ADHD in their future classrooms, it is equally important for pre-service teachers to be well prepared to effectively manage students with ADHD in the future. Having a comprehensive understanding (e.g. factual knowledge) of ADHD is the initial step to help pre-service teachers to prepare for their work (Canu \& Mancil, 2012). In actuality, even in-service teachers have a lack of information of ADHD. They may be unable to deal effectively with the needs of these children (Wolraich \& DuPaul, 2010), which also concerns pre-service teachers. Pre-service teachers also need to improve their understanding of ADHD (Lee, Lammers, \& Witruk, 2015).

The absence of knowledge can leave space for misconceptions that will impact the teachers' perception of their ability to work with a child diagnosed with ADHD and their perception of the child's ability to perform academically and behaviorally (Ballantine, 2015).

The success of students with ADHD in an inclusion classroom depends on how their teachers provide these students with appropriate education and support (Kos et al., 2006). Besides, teachers as significant persons can give extraordinary help for children with ADHD in the classroom. For instance, adults who had ADHD in childhood reported about their overcoming of Disabilities through their teachers' professional guidance and care, which acted as a turning point for coping with their disorders (Barkley, 2007).

To date, there are few investigations of pre-service teachers' knowledge concerning ADHD, including all aspects of the disease e.g. pathogenesis, signs and symptoms, diagnosis and treatment, has ever been operated in Saudi Arabia. Accordingly, the present study was aimed primarily to provide a systematic assessment of knowledge regarding ADHD of pre-service special education teachers in Saudi Arabia, as well as determine the effect of variables (Gender, track or specialty, school year or university level).

\subsection{Teachers' Knowledge of ADHD}

The work of the teacher becomes more demanding when some learners have Attention Deficit Hyperactivity Disorder (ADHD), as their troubles with activity level often obstruct classroom activities (DuPaul \& Stoner, 2003) American Academy of Pediatrics emphasizes the importance of teachers' role in managing a child with ADHD (5th ed; DSM-5; American Psychiatric Association, 2013). Since pre-service teachers are very likely to have to manage students with ADHD, it is equally important for pre-service teachers to have correct knowledge of ADHD (Bekle, 2004; Kang et al., 2011; Lee et al., 2015).

Several studies from different parts of the world have found that teachers' knowledge is at best reasonable and in many cases, insufficient, requiring intervention (e.g., Bekle, 2004; Alshboul, 2017; Suleiman, 2015; Dilaimi, 2013; Guerra \& Brown, 2012; Mulholland, 2016; Alkahtani, 2013; Ballantine, 2015; Alamri, 2014; Safaan et al., 2017; Lee et al., 2015; Soroa et al., 2016; Lee, 2017). 
Sciutto et al. (2000) agree with Jerome et al. (1994) with respect to their discoveries that teachers hold misconceptions about ADHD. Of the 149 elementary school teachers who completed the Knowledge of Attention Deficit Disorders Scale (KADDS) assessment, Sciutto et al. (2000) found that educators' scores on the symptoms/diagnosis subscale were significantly higher than scores on both the general information and treatment subscales. Previous experience and exposure to ADHD were positively related to knowledge of the disorder (Sciutto et al., 2000).

Moreover, Weyandt, Fulton, Shepman, Verdi, and Wilson (2009) surveyed a sample of 132 teachers (general and special education) from kindergarten through grade 12 as well as school psychologists (by completing a 24-item questionnaire) about treatment and possible causes of ADHD. It was found that the results supported the hypothesis that school psychologists' knowledge level of ADHD will be significantly greater than that of general and special educators. Results did not support the hypothesis that special educators' level of knowledge would be significantly greater than that of general educators.

Kang et al. (2011) analyzed 204 Korean elementary school teachers' knowledge of ADHD using KADDS (Sciutto et al., 2000). The average of their knowledge scope was 53.3\%. No evidence was found about what teachers know incorrectly (inaccuracy) or do not know (no information rate) about ADHD.

As for specific knowledge in terms of correct responses, $48.9 \%$ of teachers correctly understand ADHD characteristics (e.g. "Children with ADHD are more distinguishable from normal children in a classroom setting than in a free play situations"; correct answer: yes), 59.3\% of teachers were found to correctly know the symptoms/diagnosis (e.g. "ADHD children often fidget or squirm in their seats"; correct answer: yes), and 54.3\% of teachers correctly knew its treatment/ management (e.g. "Parent and teacher training in managing an ADHD child are generally effective when combined with medication treatment"; correct answer: yes).

A similar research was conducted in Germany. Schmiedeler (2013) investigated 353 primary and secondary school teachers using KADDS (Sciutto et al., 2000). 54.2\% of teachers' knowledge was found to be correct (accuracy), $16.9 \%$ of teachers were found to believe information that was wrong (inaccuracy), and $28.8 \%$ of teachers had no in- formation (no information rate). As for specific knowledge of correct responses, $43.9 \%$ of teachers correctly knew ADHD characteristics (e.g. "It is possible for an adult to be diagnosed with ADHD"; correct answer: yes), $72.6 \%$ of teachers correctly knew the symp- toms/diagnosis (e.g. "ADHD children are frequently distracted by extraneous stimuli"; correct answer: yes), and $53.1 \%$ of teachers correctly knew the treatment/management (e.g. "If an ADHD child is able to demonstrate sustained attention to video games or TV for over an hour, that child is also able to maintain attention for at least an hour of class or homework"; correct answer: no).

Teachers who participated in the ADHD-related training were observed to have greater knowledge than those with less or no such experience (Lee \& Witruk, 2016b; Murray, 2010). In addition, special education teachers seemed to have a working knowledge of the nature of ADHD as a disorder compared to non-special education teachers. Bekle (2008) found that teachers answered knowledge-based questions more accurately than undergraduate students. This finding differs from Jerome et al. (1999, as cited in Bekle, 2008) indicating that factual knowledge about ADHD was similar among teachers and undergraduate students. Kos (2004) assessed knowledge of ADHD among primary in-service and pre-service teachers.

Although differences in levels of knowledge of ADHD were found through questionnaire responses between the groups, it was concluded that there was a deficit in knowledge of ADHD among both groups of teachers. Abed, Pearson, Clarke, and Chambers (2014) found that Saudi Arabian teachers showed some knowledge of the general characteristics of ADHD but had little understanding of causes and possible interventions. The requirement for increasingly formal teacher training regarding ADHD was also discussed. Al-Omari, Al-Motlaq, and Al-Modallal (2015) found that many misconceptions about the causes and management of ADHD among Jordanian teachers were revealed. The need for reforming pre-service teacher preparation regarding supporting students with ADHD was noted. Although a number of studies have consistently investigated in-service teachers' knowledge of ADHD (e.g. Lee \& Witruk, 2016), only a handful has researched pre-service teachers (e.g. Lee et al., 2015).

Various examinations have found that if teachers have more accurate knowledge of ADHD, they may have a better understanding of ADHD children and better communication with them (Perold et al., 2010). The findings of the study by Lee et al. (2015) demonstrated that (a) pre-service teachers majoring in special education had a significantly higher level of knowledge of ADHD than those in primary education, (b) no significant difference was observed between pre-service teachers in their lower year of studies and higher year of studies, (c) pre-service teachers who learned about ADHD management skills during their university training showed a significantly higher level of knowledge than those without such experience, and (d) no significant difference was found between pre-service teachers with and without personal experience. 
Given the low number of investigations carried out in this context, this study has two main goals: (1) To examine the level of knowledge that Saudi Arabian Pre-Service Special Education Teachers' about ADHD, using an instrument that has appropriate psychometric properties; and (2) Does Saudi Arabian Pre-Service Special Education Teachers knowledge on ADHD differ according to the selected variables, Gender (male or female), track or specialty (special education ,mental disability, learning disabilities, hearing disability, behavioral disorders and Behavioral Disorders and Autism), school year or university level (first year, second year, third year, and fourth year)?

\subsection{The Current Study}

The aim of this study is to detect the level of knowledge held by Saudi Arabian Pre-Service Special Education Teachers at the Umm Al-Qura University with regard to Attention-Deficit/Hyperactivity Disorder (ADHD), And comparing their level of knowledge of Attention-Deficit/Hyperactivity Disorder (ADHD) according to variables: Gender, track or specialty, school year or university level.

The following research questions (RQ) were addressed in this study:

- RQ 1. Which particular facts are 'correctly known' or 'incorrectly known' and 'not known' by Saudi Arabian Pre-Service Special Education Teachers?

- RQ 2. Does Saudi Arabian Pre-Service Special Education Teachers knowledge on ADHD differ according to the selected variables?

\section{Method}

\subsection{Participants}

682 Saudi Arabian Pre-Service Special Education Teachers (313 males, 369 females) who were in Years 1,2,3 and 4 of a four-year Bachelor degree program and specialty (special education ,mental disability, learning disabilities, hearing disability, behavioral disorders and Autism), from the Department of Special Education at Umm Al-Qura University in Makkah Region in the Kingdom of Saudi Arabia for the academic year (1437H-1438H) (see a more detailed description of the study variables in Note of Table 1).

\subsection{Survey Instrument}

TEACHERS' KNOWLEDGE OF ADHD Most surveys that measure teachers' knowledge of ADHD is based on either Jerome, Gordonand Hustler's (1994) 20-item untitled scale or Sciutto, Terjesen and Bender Frank's (2000) 36-item Knowledge of Attention Deficit Disorders Scale. In 2016, Lee and Witruk modified the questionnaire compiled by Kos et al. (2004) to investigate Korean and German in-service teachers' knowledge of ADHD. For this current study, the same questionnaire written by Lee and Witruk (2016) was used with a slight modification for the Saudi Arabian Pre-Service Special Education Teachers sample. The modification is rewording the items using the term "Children with ADHD" instead of "ADHD Children".

Knowledge of ADHD. The questionnaire consists of 22 items (in a true/false/don't know format) to assess what pre-service teachers correctly know (accuracy), incorrectly know (inaccuracy), and do not know (no information) about ADHD. The possible range of scores was from 0 to 44 points ('correctly known': 2 points; 'incorrectly known': 1 point; 'not known': 0 points). Higher scores reflect a higher level of knowledge of ADHD. The internal consistency of the study by Lee and Witruk (2016) was 0.745, and this Saudi Arabia version of the knowledge of attention deficit disorder scale (KADDS) demonstrated high reliability with Cronbach's alpha 0.762 . 
Table 1. Frequencies and percentages of pre-service teachers' characteristics

\begin{tabular}{llll}
\hline Variables & & Frequency & Percent \\
\hline \multirow{2}{*}{ Sex } & Male & 313 & 45.9 \\
& Female & 369 & 54.1 \\
\hline \multirow{3}{*}{ Year } & $1^{\text {st }}$ & 16 & 2.3 \\
& $2^{\text {nd }}$ & 70 & 10.3 \\
& $3^{\text {rd }}$ & 50 & 7.3 \\
& $4^{\text {th }}$ & 546 & 80.1 \\
\hline \multirow{3}{*}{ Major } & Special Education & 86 & 12.6 \\
& Mental retardation & 150 & 22.0 \\
& Hearing impaired & 160 & 23.5 \\
& behavioral disorders and Autism) & 143 & 21.0 \\
\hline Total & learning Disabilities & 143 & 21.0 \\
\hline
\end{tabular}

Note. Three selected variables. Gender (males, females), the first, second, third and fourth year of a Bachelor programme, and specialty (special education,mental disability, learning disabilities, hearing disability, behavioral disorders and Autism).

\subsection{Data Collection}

The Dean of the Faculty of Education at Umm Al Qura University was asked for permission to recruit education students via e-mail and during school schedule. The e-mail contained a hyperlink to the pre-service version of the online survey, (682) percent of pre-service teachers who entered the site for the survey completed it. Submission of responses was taken as consent. The online survey took approximately 45 minutes to complete.

\subsection{Data Analysis}

Several mean analyses were conducted to compare Saudi Arabia Pre-Service Special Education Teachers knowledge of ADHD based on three selected variables (Gender, track or specialty, school year or university level), Descriptive Statistics, T and F tests, Frequencies and Percentages analysis of Pre-service Teachers' Characteristics. In addition, Pairwise Multiple Comparisons Post Hoc Test using LSD method was conducted.

\section{Results}

\subsection{Knowledge of ADHD (RQ 1 Findings)}

Saudi Arabian Pre-Service Special Education teachers' knowledge of attention deficit hyperactivity disorders.

The participants in this study answered (64.2\%) of the statements about ADHD correctly. They had misconceptions about $(33.6 \%)$ of the statements and they were uncertain about $(2.1 \%)$ of the statements. A different pre-service teacher sample from an earlier study achieved $52.60 \%$ correct answers (Kos et al., 2004). This result is similar to what we found.

A frequency analysis was used to investigate what Saudi Arabian Pre-Service Special Education Teachers know correctly or incorrectly, as well as to find out about a complete lack of information about ADHD. Table 2 presents - pre-service teachers' responses general knowledge of ADHD (from Murray, 2010) and criteria of the data analysis (e.g. high, rather low).

Correctly known. "Students with ADHD cannot sit still long enough to pay attention" (correct answer: false) and "Students with ADHD always need a quiet environment to concentrate" (correct answer: false) turned out to be the most correctly answered items. The correct rate of knowledge of ADHD was $93.0 \%$ and 86.8 ('high'), respectively.

Incorrectly known. "ADHD affects male students only" (correct answer: false) and "Diets are usually not helpful in treating most students with ADHD." (correct answer: true) turned out to be the most incorrectly answered items. The incorrect rate of this knowledge was $82.1 \%$ and $73.6 \%$ ('rather high'), respectively.

Not known. "The cause of ADHD is not completely known" (correct answer: true) and "The cause of ADHD is not completely known" (correct answer: true) were the items that were most frequently answered to as 'not known'. 
The 'not known' rate was $11.7 \%$ ('rather low').

Table 2. Percentage of correctly known, incorrectly known and not known items for Saudi Arabia pre-service special education teachers

\begin{tabular}{|c|c|c|c|c|c|c|c|}
\hline \multirow[t]{2}{*}{ \# } & \multirow[t]{2}{*}{ Description } & \multicolumn{2}{|c|}{$\begin{array}{l}\text { Correctly } \\
\text { known }\end{array}$} & \multicolumn{2}{|c|}{$\begin{array}{l}\text { Incorrectly } \\
\text { known }\end{array}$} & \multicolumn{2}{|c|}{ Don't know } \\
\hline & & Count & $\%$ & Count & $\%$ & Count & $\%$ \\
\hline 1 & $\begin{array}{l}\text { ADHD can be diagnosed in the doctor office most of the time. } \\
\text { (False) }\end{array}$ & 314 & 46.0 & 360 & 52.8 & 8 & 1.2 \\
\hline 2 & $\begin{array}{l}\text { Approximately } 5 \% \text { of Saudi Arabia school-aged students have } \\
\text { ADHD. (True) }\end{array}$ & 546 & 80.1 & 120 & 17.6 & 16 & 2.3 \\
\hline 3 & $\begin{array}{l}\text { Diets are usually not helpful in treating most students with } \\
\text { ADHD. (True) }\end{array}$ & 180 & 26.4 & 502 & 73.6 & 0 & .0 \\
\hline 4 & $\begin{array}{l}\text { A student who is not over-active but fails to pay attention can } \\
\text { have ADHD. (True) }\end{array}$ & 362 & 53.1 & 320 & 46.9 & 0 & .0 \\
\hline 5 & $\begin{array}{l}\text { Students with ADHD always need a quiet environment to } \\
\text { concentrate. (False) }\end{array}$ & 592 & 86.8 & 74 & 10.9 & 16 & 2.3 \\
\hline 6 & ADHD students are usually from single parent families. (False) & 298 & 43.7 & 384 & 56.3 & 0 & .0 \\
\hline 7 & All students with ADHD are overactive. (False) & 522 & 76.5 & 160 & 23.5 & 0 & .0 \\
\hline 8 & There are several subtypes of ADHD. (True) & 552 & 80.9 & 122 & 17.9 & 8 & 1.2 \\
\hline 9 & ADHD affects male students only: (False) & 114 & 16.7 & 560 & 82.1 & 8 & 1.2 \\
\hline 10 & $\begin{array}{l}\text { If a student can play Nintendo for hours, then s/he probably } \\
\text { doesn't have ADHD. (False) }\end{array}$ & 332 & 48.7 & 342 & 50.1 & 8 & 1.2 \\
\hline 11 & $\begin{array}{l}\text { Students with ADHD cannot sit still long enough to pay } \\
\text { attention. (False) }\end{array}$ & 634 & 93.0 & 40 & 5.9 & 8 & 1.2 \\
\hline 12 & Students from any walk of life can have ADHD. (True) & 476 & 69.8 & 198 & 29.0 & 8 & 1.2 \\
\hline 13 & $\begin{array}{l}\text { Students with ADHD usually have good peer relations because of } \\
\text { their outgoing nature. (False) }\end{array}$ & 258 & 37.8 & 416 & 61.0 & 8 & 1.2 \\
\hline 14 & $\begin{array}{l}\text { Students with ADHD generally display an inflexible adherence } \\
\text { to specific routines or rituals. (False) }\end{array}$ & 546 & 80.1 & 128 & 18.8 & 8 & 1.2 \\
\hline 15 & The cause of ADHD is not completely known (True) & 492 & 72.1 & 110 & 16.1 & 80 & 11.7 \\
\hline 16 & $\begin{array}{l}\text { ADHD students are born with biological vulnerabilities toward } \\
\text { inattention and poor self-control. (True) }\end{array}$ & 502 & 73.6 & 172 & 25.2 & 8 & 1.2 \\
\hline 17 & ADHD is often caused by food additives. (False) & 578 & 84.8 & 96 & 14.1 & 8 & 1.2 \\
\hline 18 & ADHD can be inherited. (True) & 414 & 60.7 & 244 & 35.8 & 24 & 3.5 \\
\hline 19 & The cause of ADHD is not completely known (True) & 546 & 80.1 & 56 & 8.2 & 80 & 11.7 \\
\hline 20 & ADHD is the result of poor parenting practices. (False) & 350 & 51.3 & 316 & 46.3 & 16 & 2.3 \\
\hline 21 & ADHD is caused by too much sugar in the diet. (False) & 456 & 66.9 & 218 & 32.0 & 8 & 1.2 \\
\hline \multirow[t]{2}{*}{22} & $\begin{array}{l}\text { Family dysfunction can increase the likelihood that a student will } \\
\text { be diagnosed with ADHD. (True) }\end{array}$ & 576 & 84.5 & 106 & 15.5 & 0 & .0 \\
\hline & Total & 9640 & $64.2 \%$ & 5044 & $33.6 \%$ & 320 & $2.1 \%$ \\
\hline
\end{tabular}

'True' and 'False' represent the correct answer for each item. Criteria of data analysis: (a) Very low: 0-10\%; (b) Low: 11-30\%; (c) Rather low: 31-50\%; (d) Rather high: 51-70\%; (f) High: 71-90\%; (g) Very high: $91-100 \%$.

\subsection{Knowledge of ADHD with Selected Variables (RQ 2)}

Several mean analyses were conducted to compare Saudi Arabia Pre-Service Special Education Teachers 
knowledge of ADHD based on three selected variables.

As shown in Table 3, Gender, track or specialty, school year or university level were found to have a significant difference between the sub-groups. As for the Gender differences were in favor of females, as for university level and specialty variables Pairwise Multiple Comparisons Post Hoc Test using LSD method was conducted as in Tables 4, 5 .

Table 3. Descriptive Statistics, T and F tests on Saudi Arabia pre-service special education teachers' knowledge of ADHD by selected variables

\begin{tabular}{|c|c|c|c|c|c|}
\hline & Demographics & $\mathbf{N}$ & Mean & Std. Deviation & $t / F$ \\
\hline \multirow{2}{*}{ Sex } & Male & 313 & 35.30 & 3.771 & \multirow{2}{*}{$2.699 * *$} \\
\hline & Female & 369 & 35.98 & 2.807 & \\
\hline \multirow{4}{*}{ Year } & $1^{\text {st }}$ & 16 & 33.13 & 2.306 & \multirow{4}{*}{$8.311 * * *$} \\
\hline & $2^{\text {nd }}$ & 70 & 34.46 & 5.689 & \\
\hline & $3^{\text {rd }}$ & 50 & 35.12 & 2.282 & \\
\hline & $4^{\text {th }}$ & 546 & 35.95 & 2.900 & \\
\hline \multirow{5}{*}{ Major } & $\begin{array}{l}\text { Special } \\
\text { Education }\end{array}$ & 86 & 34.77 & 2.574 & \multirow{5}{*}{$5.077^{* * *}$} \\
\hline & $\begin{array}{l}\text { Mental } \\
\text { retardation }\end{array}$ & 150 & 35.55 & 3.574 & \\
\hline & Hearing impaired & 160 & 35.28 & 3.804 & \\
\hline & Autism & 143 & 35.85 & 2.943 & \\
\hline & $\begin{array}{l}\text { learning } \\
\text { Disabilities }\end{array}$ & 143 & 36.57 & 2.911 & \\
\hline
\end{tabular}

Note. The possible range of knowledge scores was from 0 to 44. $S D=$ standard deviation. See Note in Table 1 for specific explanations of the five selected variables. $* * * p<0.001, * * p<0.01, * p<0.05$.

Table 4. Pairwise Multiple Comparisons Post Hoc Tests using LSD method due to year variable

\begin{tabular}{|c|c|c|c|c|}
\hline (I) Year & (J) Year & Mean Difference (I-J) & Std. Error & Sig. \\
\hline & 2 & -1.33 & .900 & .139 \\
\hline \multirow[t]{3}{*}{$1^{\text {st }}$} & $3^{\text {rd }}$ & $-1.99(*)$ & .933 & .033 \\
\hline & $4^{\text {th }}$ & $-2.82(*)$ & .824 & .001 \\
\hline & $1^{\text {st }}$ & 1.33 & .900 & .139 \\
\hline \multirow[t]{3}{*}{$2^{\text {nd }}$} & $3^{\text {rd }}$ & -.66 & .601 & .271 \\
\hline & $4^{\text {th }}$ & $-1.49(*)$ & .412 & .000 \\
\hline & $1^{\text {st }}$ & $1.99(*)$ & .933 & .033 \\
\hline \multirow[t]{3}{*}{$3^{\text {rd }}$} & $2^{\text {nd }}$ & .66 & .601 & .271 \\
\hline & $4^{\text {th }}$ & -.83 & .480 & .086 \\
\hline & $1^{\text {st }}$ & $2.82(*)$ & .824 & .001 \\
\hline \multirow[t]{2}{*}{$4^{\text {th }}$} & $2^{\text {nd }}$ & $\left.1.49{ }^{*}\right)$ & .412 & .000 \\
\hline & $3^{\text {rd }}$ & .83 & .480 & .086 \\
\hline
\end{tabular}

* The mean difference is significant at the .05 level.

The table shows that there is a statistically significant difference at $(\alpha=0.05)$ between first year and the third year in favor of the third year, between first year and fourth year in favor of the fourth year and between second year and 
fourth year in favor of the fourth year.

Table 5. Pairwise Multiple Comparisons Post Hoc Tests using LSD method due to major variable

\begin{tabular}{lllll}
\hline (I) Major & (J) Major & Mean Difference (I-J) & Std. Error & Sig. \\
\hline \multirow{4}{*}{ Special Education } & Mental retardation & -.79 & .441 & .075 \\
& Hearing impaired & -.51 & .436 & .239 \\
& Autism & $-1.09\left(^{*}\right)$ & .445 & .015 \\
& Learning Disabilities & $-1.80\left(^{*}\right)$ & .445 & .000 \\
\hline \multirow{4}{*}{ Mental retardation } & Special Education & .79 & .441 & .075 \\
& Hearing impaired & .27 & .371 & .463 \\
& Autism & -.30 & .381 & .432 \\
& Learning Disabilities & $-1.01\left(^{*}\right)$ & .381 & .008 \\
\hline \multirow{4}{*}{ Hearing impaired } & Special Education & .51 & .436 & .239 \\
& Mental retardation & -.27 & .371 & .463 \\
& Autism & -.57 & .375 & .128 \\
& Learning Disabilities & $-1.29\left(^{*}\right)$ & .375 & .001 \\
\hline \multirow{5}{*}{ Autism } & Special Education & $1.09\left(^{*}\right)$ & .445 & .015 \\
& Mental retardation & .30 & .381 & .432 \\
& Hearing impaired & .57 & .375 & .128 \\
& Learning Disabilities & -.71 & .386 & .065 \\
\hline \multirow{5}{*}{ Learning Disabilities } & Special Education & $1.80\left(^{*}\right)$ & .445 & .000 \\
& Mental retardation & $1.01\left(^{*}\right)$ & .381 & .008 \\
& Hearing impaired & $1.29\left(^{*}\right)$ & .375 & .001 \\
& Autism & .71 & .386 & .065 \\
\hline
\end{tabular}

* The mean difference is significant at the .05 level.

The table shows that there is a statistically significant difference at $(\alpha=0.05)$ between special education and autism in favor of autism, between special education and learning Disabilities in favor of learning Disabilities, between mental retardation and learning Disabilities in favor of learning Disabilities, and between hearing impaired and learning Disabilities in favor of learning Disabilities.

\section{Discussion}

Attention Deficit Hyperactivity Disorder (ADHD) often poses a significant problem in the classroom for students and teachers. An estimated $8.4 \%$ of Saudi children were diagnosed with ADHD.

The data analysis indicated that the levels of knowledge of ADHD among Pre-Service Special Education Teachers in Saudi Arabian are rather high, with scale knowledge scores ranging from (93.0\%-11.7\%), the correct rate of knowledge of ADHD was $93.0 \%$ and 86.8 ('high'), The incorrect rate of this knowledge was $82.1 \%$ and $73.6 \%$ ('rather high'), The 'not known' rate was $11.7 \%$ ('rather low').

Our findings provide insight into the area of teacher preparation of students with ADHD. General knowledge had a rather high score from the study sample. These findings highlight the fact that institutions of higher education in Saudi Arabia have been successful in the special education preparation of Special Education teachers.

A large number of resources in time, effort, staff development, curriculum, and implementation appear to have a significant impact on pre-teacher preparedness to deal specifically with students with ADHD.

We have a responsibility towards our children to make sure that teachers are knowledgeable about ADHD and that they are in a position to offer support to children in order for them to manage their behavior and achieve success both socially and academically (Perold et al., 2010). 
Based on the review of the literature, much research supports the idea that familiarity with teaching students diagnosed with ADHD connects to teachers' having increased knowledge (Kos et al., 2004). The results from this study concur with the results found in separate studies by (Lee et al., 2015). German pre-service teachers' accuracy (51.60\%), Seventy-two percent of the Male Primary School Teachers in Riyadh, Saudi Arabia had either very good (13\%) or good (59\%) knowledge about ADHD (Aldawodi et al., 2018).

However, it is consistent with (Dilaimi, 2013); New Zealand teachers' accuracy on the KADDS 35\%, (Lee, 2017) Korean-service teachers' accuracy (42.28\%), (Soroa et al., 2016) the study which analyzes Teachers' knowledge of ADHD ranged from low to moderate. Also, there was $59 \%$ of teachers had poor knowledge (Safaan et al., 2017), Teachers' knowledge of ADHD STUDENTS WITH ADHD-RELATED BEHAVIOURS was found limited (Alamri, 2014), and only 19.4\% of teachers passed the total scale of KADDS (Muanprasart et al., 2014), Knowledge about children with ADHD was generally limited (Kikasa \& Timoštšukb, 2015).

The main effects of the independent variables "Gender", "track or specialty", and "university level" and their interactions were analyzed for the dependent variable Knowledge of ADHD. As for the Gender differences were in favor of females, this results not consistent with (Kos et al., 2004; Youssef et al., 2015). It is noteworthy that although there was a significant difference in knowledge levels between male and female pre-teachers, this can be justified because the sample was overrepresented by female pre-teachers.

There is a statistically significant difference between first year and third year in favor of the third year, between first year and fourth year in favor of the fourth year and between second year and fourth year in favor of the fourth year. The exact reasons for this, the pre-teacher in the third and fourth year have taken a number of ADHD courses or workshops in college and graduate level.

This result could be a good point to have in mind as pre-service teachers in the first and second year do not know enough about ADHD but still, have an opportunity to learn the ADHD epidemiology through Special Education Curriculum. It seems to be necessary to integrate more information and training about ADHD into the curriculum for the first and second-year special education pre-teachers. This matches previous research which showed that teachers know more about ADHD if they have attended ADHD training (Kos et al., 2004; Vereb \& DiPerna, 2004; West et al., 2005; Schmiedeler, 2013; Suleiman, 2015; Alkahtani, 2013; Safaan et al., 2017; Shaaban, 2014), This results not consistent with (Guerran \& Brown, 2012).

Pairwise Multiple Comparisons demonstrated significant knowledge advantages for track or specialty (Autism and Learning Disabilities), this is due to these two specialties that teaches practical courses in ADHD, and many courses focusing on this disorder. The results indicate that future special education teachers know more about ADHD and know more about this disorder if it is discussed during their education. The results concur with (Lee et al., 2015) and (Safaan et al., 2017), the results of the study showed that there was a significant relationship between mean score of total teachers' knowledge and reading book or an article about ADHD, but not consistent with (Alshboul, 2017) and (Suleiman, 2015).

The findings also refer to the need for modifications in (Special Education, Mental retardation and, Hearing Impaired) education curriculum. KADDS scores of Pre-Service Special Education Teachers increase as teachers become more familiar and have more information about ADHD. Further research could compare other demographics to determine other reasons for pre-teachers lack of knowledge.

\section{General Recommendations}

1). Faculty of Education should include condition-specific (including ADHD) student development programs as a continuing activity to improve the learning experiences of all children.

2). Institutions of higher education should enhance pre-teacher preparation courses to address conditions or disorders that affect students with ADHD.

3). This study can also be regarded as a resource for modifying university education to provide Pre-Service Special Education Teachers in Saudi Arabian with greater opportunities to learn about ADHD and to successfully apply correct knowledge when being prepared to manage future students with ADHD.

\section{Competing Interests Statement}

The authors declare that there are no competing or potential conflicts of interest.

\section{References}

Alamri, S. (2014). Students with ADHD-related behaviors: Saudi mainstream teachers' knowledge and attitude towards inclusion (Doctoral dissertation, Queensland University of Technology, Brisbane, Australia). 
Aldawodi, M., Al-Harthy, N., Masud, N., Alfageer, H., Qureshi, S. H., \& Alrabah, M. (2018). Knowledge and Attitude of Male Primary School Teachers about Attention Deficit and Hyperactivity Disorder in Riyadh, Saudi Arabia. The Journal of Natural Science, Biology and Medicine, 9(2). https://doi.org/10.4103/jnsbm.JNSBM_232_17

Alkahtani, K. D. (2013). Teachers' knowledge and misconceptions of ADHD. Psychology, 4(12), 963-969. https://doi.org/10.4236/psych.2013.412139

American Academy of Pediatrics. (2000). Clinical practice guideline: diagnosis and evaluation of the child with attention-deficit/hyperactivity disorder. Pediatrics, 105, 1158-70. https://doi.org/10.1542/peds.105.5.1158

American Psychiatric Association. (2013). Diagnostic and statistical manual of mental disorders (5th ed., pp. 59-65). Washington, American Psychiatric Publishing.

Alshboul, M. (2017). The Perceptions of the elementary school teachers in Jordan towards Attention Deficit Hyperactivity Disorder (ADHD), alfateh magazine, Sixty-ninth. March of 2017.

Ballantine, C. (2015). Teacher Knowledge and Perception of Students with an ADHD Label. All Capstone Projects. 113. P. 4

Barbaresi, W. J., Katusic, S. K., Colligan, R. C., Pankratz, V. S., Weaver, A. L., Weber, K. J., ... \& Jacobsen, S. J. (2002). How common is Attention-Deficit/Hyperactivity Disorder? Incidence in a population-based birth cohort in Rochester, Minn. Archives of Pediatric and Adolescent Medicine, 156, 217-224. https://doi.org/10.1001/archpedi.156.3.217

Barkley, R. (2006). ADHD: A handbook for diagnosis and treatment (3rd ed.). New York: Guilford Press.

Barkley, R. A. (2007). School interventions for attention deficit hyperactivity disorder: Where to from here? School Psychology Review, 36, 279-286

Barkley, R. A., Murphy, K. R., \& Fischer, M. (2008). ADHD in Adult: What the Science says. New York: Guilford Press.

Bekle, B. (2004). Knowledge and attitudes about attention-deficit hyperactivity disorder (ADHD): a comparison between practicing teachers and undergraduate education students. Journal of Attention Disorders, 7(3), 151-161. https://doi.org/10.1177/108705470400700303

Bener, A., Al-Qahtani, R., \& Abdelaal, I. (2006). The prevalence of ADHD among primary school children in an Arabian Society. J Atten Dis., 10, 77-82. https://doi.org/10.1177/1087054705284500

Canu, W., \& Mancil, E. (2012). An examination of teacher trainees' knowledge of attention-deficit/hyperactivity disorder. School Mental Health, 4, 105-114. https://doi.org/10.1007/s12310-012-9071-3

Dilaimi, A. (2013). New Zealand primary school teachers' knowledge and perceptions of ADHD. (Published master theses, Massey University, Albany, New Zealand). https://doi.org/10.5114/cipp.2017.66261

DuPaul, G. J., \& Stoner, G. (2003). ADHD in the schools: Assessment and instructional strategies (2nd ed.). New York, NY: Guilford Press.

Guerra, J. F. R., \& Brown, M. S. (2012). Teacher knowledge of ADHD among middle school students in South Texas. Research in middle level education online, 36(3), 1-7.

Hanna, N. (2009). Attention Deficit Disorder (ADD) Attention Deficit Hyperactive Disorder (ADHD) Is it a product of our modern lifestyles? American Journal of Clinical Medicine, 6(4).

Kang, K. R., Kim, Y. H., \& Yang, Y. O. (2011). Teaching status and knowledge of elementary school teachers of children with attention deficit hyperactivity disorder. Journal of Korean Academy of Child Health Nursing, 17(2), 136-144. https://doi.org/10.4094/jkachn.2011.17.2.136

Kos, J. M., Richdale, A. L., \& Jackson, M. S. (2004). Knowledge about attention deficit hyperactivity disorder: A comparison of in-service and preservice teachers. Psychology in the Schools, 41(5), 517-526. https://doi.org/10.1002/pits.10178

Kos, J., Richdale, A., \& Hay, D. (2006). Children with attention deficit hyperactivity disorder and their teachers: A review of the literature. International Journal of Disability Development and Education, 53, 147-160. https://doi.org/10.1080/10349120600716125

Lee, Y., Lammers, H. S., \& Witruk, E. (2015). Knowledge of attention deficit hyperactivity disorder (ADHD): a comparison of pre-service teachers in primary and special education in Germany. Health Psychology Report, 
3(3), 237-245. https://doi.org/10.5114/hpr.2015.54104

Lee, Y., \& Witruk, E. (2016b). Teachers' knowledge, perceived teaching efficacy, and attitudes regarding students with ADHD: a cross-cultural comparison of teachers in South Korea and Germany. Health Psychology Report, 4(2), 103-115. https://doi.org/10.5114/hpr.2016.58383

Lee, Y. (2015). Teachers' attitudes, knowledge, and classroom management strategies regarding students with ADHD: A cross-cultural comparison of teachers in South Korea and Germany (Unpublished doctoral dissertation). University of Leipzig, Leipzig, Germany.

Masi, L., \& Gignac, M. (2015). ADHD and Comorbid Disorders in Childhood Psychiatric Problems, Medical Problems, Learning Disorders and Developmental Coordination Disorder. Clinical Psychiatry, 2015. https://doi.org/10.21767/2471-9854.100005

Mayes, S., Calhoun, S., \& Crowell, E. (2000). Learning disabilities and ADHD: Overlapping spectrum disorders. Journal of Learning Disabilities, 33, 417-424. https://doi.org/10.1177/002221940003300502

Muanprasart, P., Traivaree, C., Arunyanart, W., \& Teeranate, C. (2014) Knowledge of attention deficit hyperactivity disorder and its associated factors among teachers in 3 large primary schools in Phra Nakorn Sri Ayutthaya province, Thailand. J Med Assoc Thai, Suppl 2, S107-14.

Mulholland, S., Cumming, T., \& Jung, J. (2015). Teacher attitudes towards students who exhibit ADHD type behaviours. Australasian Journal of Special Education, 39, 15-36. https://doi.org/10.1017/jse.2014.18

Mulholland, S. (2016). ADHD-specific knowledge and attitudes of teachers (ASKAT): Development and validation of a new research instrument. International Journal of Educational Research, 77(2016), 109-116. https://doi.org/10.1016/j.ijer.2016.03.010

Murray, E. (2010). "Don't give up on them": Managing attention deficit hyperactivity disorder in school - What teachers and parents believe and know (Unpublished doctoral dissertation). Murdoch University, Perth, Australia.

Norvilitis, J., \& Fang, P. (2005). Perceptions of ADHD in China and the United States: a preliminary study. Journal of Attention Disorders, 9, 413-424. https://doi.org/10.1177/1087054705281123

O'Reilly, M. J. (2002). The early literacy skill development of kindergartners and first graders at-risk for externalizing behavior disorders (Unpublished doctoral dissertation, University of Massachusetts at Amherst).

Ohan, J. L., Cormier, N., Hepp, S. L., Visser, T. A., \& Strain, M. C. (2008). Does knowledge about ADHD impact teachers' reported behaviors and perceptions? School Psychology Quarterly, 23(3), 436-449. https://doi.org/10.1037/1045-3830.23.3.436

Ohan, J. L., Vissor, T. A., Strain, M. C., \& Allen, L. (2011). Teachers' and education students' perceptions of and reactions to children with and without the diagnostic label "ADHD." Journal of School Psychology, 49, 81-105. https://doi.org/10.1016/j.jsp.2010.10.001

Al-Modayfer, O., \& Alatiq, Y. (2015). A Pilot Study on the Prevalence of Psychiatric Disorders among Saudi Children and Adolescents: A Sample from a Selected Community in Riyadh City. The Arab Journal of Psychiatry, 26(2), 184-192. https://doi.org/10.12816/0014485

Perold, H., Louw, C., \& Kleynhans, S. (2010). Primary school teachers' knowledge and misperceptions of ADHD. South African Journal of Education, 30(3), 457-473. https://doi.org/10.15700/saje.v30n3a364

Safaan, A., El-Nagar, S., \& Saleh, A. (2017). Teachers' Knowledge about Attention Deficit Hyperactivity Disorder among Primary School Children. American Journal of Nursing Research, 5(2), 42-52. https://doi.org/10.12691/ajnr-5-2-2

Sciutto, M. J., Terjesen, M. D., \& Bender-Frank, A. (2000). Teachers' knowledge and misperceptions of ADHD.

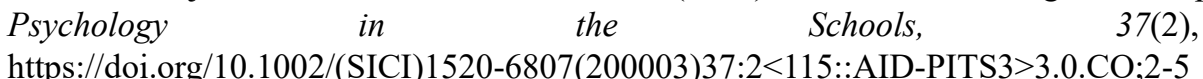

Schmiedeler, S. (2013). Wissen und Fehlannahmen von deutschen Lehrkräften über die Aufmerksamkeitsdefizit-/Hyperaktivitätsstör ng (ADHS) [German teachers' knowledge and misconceptions about attention deficit-/hyperactivity disorder (ADHD)]. Psychologie in Erziehung und Unterricht, 60(2), 143-153. https://doi.org/10.2378/peu2013.art12d 
Shaaban, N. (2014). Knowledge, perceptions and attitudes of elementary classroom teacher towards ADHD children in Egyptian international schools. Institute of Education, University of London.

Soroa, M., Gorostiaga, A. \& Balluerka, N. (2012). Review of tools used for assessing teacher's level of knowledge with regards ADHD. In S. Banerjee (Ed.), ADHD in children and adolescents. South Korea and Germany. Current Issues in Personality Psychology, 5(2), 102-112.

Suleiman, M. E. (2015). Primary school teachers' knowledge of ADHD in Beni-Suef governorate in Egypt. The Islamic University of Educational and Psychological Studies Journal, 23(1), 98-121.

Vereb, R. L., \& DiPerna, J. (2004). Teachers' knowledge of ADHD, treatments for ADHD, and treatment acceptability: An initial investigation. School Psychology Review, 33(3), 421-428.

Wehmeier P. M., Schacht, A., \& Barkley, R. A. (2010). Social and emotional impairment in children and adolescents with ADHD and the impact on quality of life. $J$ Adolesc Health, 46(3), 209-17. https://doi.org/10.1016/j.jadohealth.2009.09.009

West, J., Taylor, M., Houghton, S., \& Hudyma, S. (2005). A comparison of teachers' and parent's knowledge and beliefs about attention- deficit/hyperactivity disorder (ADHD). School Psychology International, 26(2), 192-208. https://doi.org/10.1177/0143034305052913

Wolraich, M. L., \& DuPaul, G. J. (2010). ADHD diagnosis and management: a practical guide for the clinic and the classroom. Baltimore, MD: Brookes Publishing.

Youssef, M. K., Hutchinson, G., \& Youssef, F. F. (2015). Knowledge of and Attitudes Toward ADHD Among Teachers: Insights From a Caribbean Nation. https://doi.org/10.1177/2158244014566761

\section{Copyrights}

Copyright for this article is retained by the author(s), with first publication rights granted to the journal.

This is an open-access article distributed under the terms and conditions of the Creative Commons Attribution license (http://creativecommons.org/licenses/by/4.0/). 